\title{
Transient Performance Analysis of Reactive Power Compensators at LCC-HVDC Station Feeding Weak AC System
}

\author{
Atiq Ur Rehman ${ }^{1 a}$, Mehr Gul ${ }^{1 b}$, Talha Mir ${ }^{2 a}$, Syed Mudassir Hussain ${ }^{2 b}$, Zahid Rauf ${ }^{3}$
}

RECEIVED ON 19.10.2020, ACCEPTED ON 16.12.2020

\begin{abstract}
This paper focuses on analyzing the dynamic performance of various reactive power compensators at weak LCC-HVDC terminals. Four scenarios based on combination of active and passive reactive power compensation schemes are presented. The comparative performance analysis of various compensators in different types of $\mathrm{AC}$ and $\mathrm{DC}$ system faults are evaluated using electromagnetic transient simulation program PSCAD/EMTDC. The analysis shows that fixed capacitor has poor performance and results in reducing effective short circuit ratio of system, while STATCOM on the other hand, increases AC system strength and has significant performance in areas like immunity to commutation failure, suppression of temporary overvoltage, AC bus voltage regulation and fault recovery time.
\end{abstract}

Keywords: Weak LCC-HVDC System, STATCOM, Temporary Overvoltage, DC Power Recovery Time

\section{INTRODUCTION}

Line Commutated Converter (LCC) based High Voltage Direct Current Transmission (HVDC) is widely implied throughout world for transmission of power from distant parts to local AC grid stations [1, 2]. Due to rapid expansion of LCC-HVDC links, the receiving end $\mathrm{AC}$ system becomes weak. Weak AC system having high impedances and low inertia, results in various operating issues like voltage instability, limitations on power transfer, temporary overvoltages, fault recovery problems, commutation failures, harmonic resonances and frequency deviations [3]. To overcome these operating issues, various compensating equipment like Fixed Capacitor (FC), Synchronous Compensator (SC), Static Var
Compensator (SVC) and Static Synchronous Compensator (STATCOM) are utilized [4-6].

Unfortunately, few publications are available regarding design and analysis of dynamic reactive power compensators utilized for LCC-HVDC station attached into weak AC networks. Reference [3] compared different compensator schemes (Fixed Capacitors, SVC, SC, combination of SVC and SC) for LCC HVDC station attached into AC systems with SCR value of 1.5 and frequency of $60 \mathrm{~Hz}$. An RL load is considered in study system to control damping and oscillations. It is identified that weak LCC-HVDC system gives best performance in all disturbances, when combination of SVC and SC is utilized as reactive power compensating source. Reference [4]

\footnotetext{
${ }^{1}$ Department of Electrical Engineering, Balochistan University of Information Technology, Engineering and Management Sciences (BUITEMS), Quetta, Pakistan.

Email: aatiq_marwat99@yahoo.com (Corresponding Author), bmehrbuitms@gmail.com

${ }^{2}$ Department of Electronic Engineering, Balochistan University of Information Technology, Engineering and Management Sciences (BUITEMS), Quetta, Pakistan. Email: ${ }^{a}$ talha.mir@ buitms.edu.pk, ${ }^{\text {b }}$ mudassir.hussain@ @uitms.edu.pk

${ }^{3}$ Department of Information Technology, Balochistan University of Information Technology, Engineering and Management Sciences (BUITEMS), Quetta, Pakistan. Email: zahid.rauf@ buitms.edu.pk
}

This is an open access article published by Mehran University of Engineering and Technology, Jamshoro under CC BY 4.0 International License. 
design advanced static VAR compensator STATCON incorporating nine level Gate Turn-Off Thyristor (GTO) and its operating characteristics are analyzed for various faults. STATCON is then compared with SVC, SC and FC. It is assessed that STATCON has better performance than mentioned compensators, in areas like fault recovery time, voltage regulation $\mathrm{dc}$ fault recovery, while operating with AC system having low SCR value. Reference [5] compared the transient performance of STATCOM and SC for LCC-HVDC system with SCR of 1.5. An RL load is considered in study system for analysis. Both STATCOM and SC almost show equal performance during various transients. Actually when RL load is connected in parallel with $\mathrm{AC}$ bus, it results in decreasing equivalent impedance, which increases SCR value and the system becomes strong.

This paper investigates in detail the dynamic performances analysis of different reactive power compensators at weak LCC- HVDC system without connecting RL load to AC bus. Various scenarios based on passive and active shunt compensators are considered for analysis of different studies like temporary overvoltage, commutation failure and fault recovery time for various disturbances. The paper is organized in following approach:

Section 2 illustrates system strength. Section 3 gives description about study system. Section 4 includes analysis of reactive power compensators, focusing mainly on operation principle and control strategy of STATCOM. Section 5 illustrates results of study system. The paper is then finally concluded in Section 6.

\section{SYSTEM'S STRENGTH}

AC-DC system's strength is generally determined by index called Short Circuit Ratio (SCR). SCR is the ratio of short circuit capacity (S) of AC network to DC network power rating $\left(\mathrm{P}_{\mathrm{d}}\right)$, as given in (1). An AC system associated with SCR value of 2 is considered as weak $\mathrm{AC}$ system, while strong $\mathrm{AC}$ system has usually SCR $\geq 3$ [7]. SCR includes only impedance of AC source $\left(Z_{a c}\right)$ in calculation of Short circuit capacity of AC network. SCR becomes Effective Short Circuit
Ratio (ESCR), if impedances of capacitors $\left(Z_{c}\right)$ and filters $\left(Z_{\mathrm{f}}\right)$ are also included in calculation of short circuit capacity, as given in (2) [4].

$$
\begin{aligned}
& \mathrm{SCR}=\frac{\mathrm{s}}{\mathrm{P}_{\mathrm{d}}}=\frac{\mathrm{v}_{\mathrm{t}}^{2}}{\mathrm{P}_{\mathrm{d}} \cdot \mathrm{Z}_{\mathrm{ac}}}=\frac{1}{\mathrm{Z}_{\mathrm{ac}}} \mathrm{Z}_{\text {base }} \\
& \mathrm{ESCR}=\frac{\mathrm{S}-\mathrm{Q}_{\mathrm{c}}}{\mathrm{P}_{\mathrm{d}}}=\left(\frac{1}{\mathrm{Z}_{\mathrm{ac}}}+\frac{1}{\mathrm{Z}_{\mathrm{f}}}+\frac{1}{\mathrm{Z}_{\mathrm{c}}}\right) \mathrm{Z}_{\text {base }}
\end{aligned}
$$

\section{SET UP OF STUDY SYSTEM}

LCC-HVDC system based on CIGRE benchmark is used for analysis [7]. In original benchmark model, the inverter side AC system with SCR of 2.5 employs fixed capacitor and filters for providing reactive power. The six-pulse STATCOM connected to inverter side of HVDC system via converter transformer is shown in Fig.1. The STATCOM model based on voltage source converter technology is developed in PSCAD/EMTDC. The SCR is changed from 2.5 to 1.8. The AC source magnitude and phase angle is modified using steady state equations as given in Appendix A.

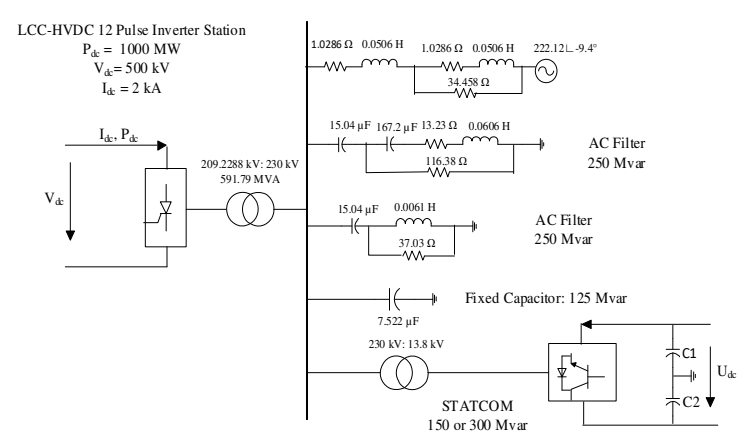

Fig.1: LCC-HVDC Inverter Station with Reactive Power Compensators, connected to Weak AC system

Four scenarios are presented in this paper to analyze behavior of LCC-HVDC system connected to weak AC system. These four scenarios comprise of different reactive power compensation schemes utilized for voltage regulation at inverter bus. In all scenarios, size of filters is kept constant. The features of four scenarios are:

Scenario 1 (Filters +Fixed Capacitor System): System is analyzed while connecting filters and passive shunt capacitors to inverter bus for supplying reactive power. At steady state, filters and fixed 
capacitor provide about 500 Mvar and 125 Mvar respectively.

\section{Scenario 2 (Filters +Fixed Capacitor + STATCOM} 150): In this scenario, STATCOM along with fixed capacitor is connected to inverter bus system. Reactive power is provided by filters and shunt capacitor in steady state while in transient state STATCOM operate to make the system stable.

Scenario 3 (Filters +STATCOM 150): Fixed capacitor is replaced by STATCOM having capacity of 150 Mvar. STATCOM provide 125 Mvar in steady and transient state. The reactive power capacity of STATCOM is kept same as that of fixed capacitor.

Scenario 4 (Filters +STATCOM 300): In this scenario, STATCOM capacity is increased to 300 Mvar. Under steady states, the reactive power supplied by filters and STATCOM is approximately $500 \mathrm{Mvar}$ and 125 Mvar respectively. In transient state, STATCOM supply surplus 150 Mvar to LCC converter station for voltage regulation at inverter $\mathrm{AC}$ bus.

\section{REACTIVE POWER COMPENSATIONS OF LCC CONVERTER STATIONS}

The reactive power requirement of LCC converter station is fulfilled by filters and shunt capacitors, when AC system is strong. However, for weak AC system, dynamic reactive power compensators like Static Var Compensator (SVC), Synchronous Condenser and STATCOM are used to regulate bus voltage. In the following section, operation principle and control mode strategy of STATCOM is presented.

\subsection{STATCOM Fundamentals}

It is a Flexible Alternating Current Transmission System (FACTS) device, shunt connected to AC transmission and distribution network for voltage regulation. Although, it is power electronics based (voltage source converter or current source converter) regulating device, its behavior is similar to Synchronous condenser. STATCOM being an active device is capable of absorbing or generating reactive power without any need of shunt reactors and capacitor banks. It can also supply active power, when energy source like battery, flywheel is connected to DC side capacitor. The schematic diagram of STATCOM is shown in Fig.2.

A B C

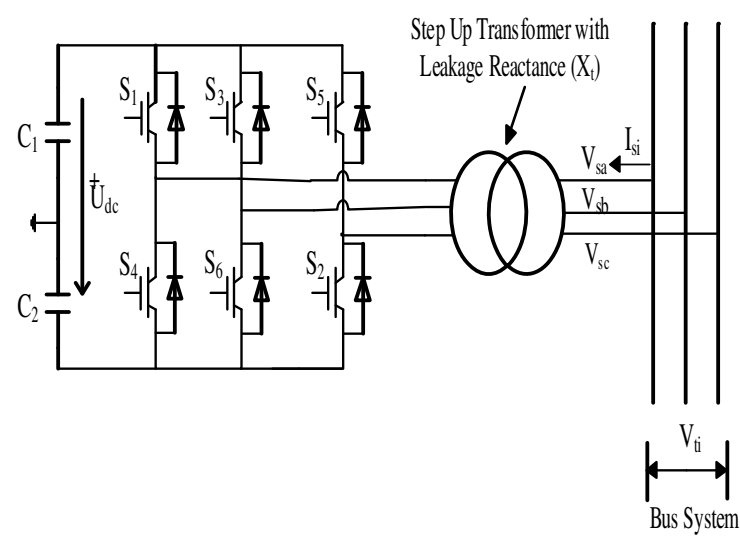

Fig.2: Detail Schematic Representation of 6-Pulse STATCOM Connected to AC bus system

where $\mathrm{V}_{\mathrm{si}}(\mathrm{i}=\mathrm{a}, \mathrm{b}, \mathrm{c})$ is the output voltage of voltage source converter. $\mathrm{V}_{\mathrm{ti}}(\mathrm{i}=\mathrm{a}, \mathrm{b}, \mathrm{c})$ is $\mathrm{AC}$ bus voltage. $\mathrm{I}_{\mathrm{si}}$ is injected current of Statcom. $U_{\mathrm{dc}}$ is capacitor voltage. $\mathrm{X}_{\mathrm{t}}$ is leakage reactance of transformer.

The phase angle difference $(\delta)$ between two voltages $\left(\mathrm{V}_{\mathrm{si}} \& \mathrm{~V}_{\mathrm{ti}}\right)$ makes possible the flow of active power which can be implied for regulations of DC voltages as given in equation (4). Moreover, the reactive power may be controlled by varying the output voltages of VSC converter as given in equation (5). If the output voltage of converter is greater than bus voltage, reactive power will be generated due to reactive current flow from converters into AC system. If output voltages of converter is less than bus voltages, reactive power will be absorbed due to reactive current flow from AC system to converter. If both voltages have same magnitude, no reactive current will be exchanged through reactor and STATCOM will be in floating state.

$$
\begin{aligned}
& \mathrm{P}_{\mathrm{s}}=\frac{\mathrm{V}_{\mathrm{ti}} \times \mathrm{V}_{\mathrm{si}}}{\mathrm{X}_{\mathrm{t}}} \cos \delta \\
& \mathrm{Q}_{\mathrm{s}}=\frac{\left(\mathrm{V}_{\mathrm{ti}}^{2} \mathrm{~V}_{\mathrm{ti}} \times \mathrm{V}_{\mathrm{si}}\right)}{\mathrm{x}_{\mathrm{t}}} \sin \delta
\end{aligned}
$$




\subsection{Control Strategy of STATCOM}

d-q decoupled control method [9] is used for controlling of STATCOM as shown in Fig. 3. It includes two close loop PI controllers. The outer loop controllers generate $\mathrm{d}$-axis and $\mathrm{q}$-axis current references $\left(\mathrm{i}_{\text {dref }} \& \mathrm{i}_{\text {qref }}\right.$ ) using dc voltages and $\mathrm{AC}$ voltages respectively as controlled parameters. The inner loop controllers are used to adjust $\mathrm{d}$-axis and qaxis currents to set with reference currents. The voltage orders $\left(\mathrm{V}_{d o}\right.$ and $\left.\mathrm{V}_{q o}\right)$ are produced by combining output of inner loop PI controllers, measured voltages and decoupling terms. These voltage orders are utilized to produce switching signals for converter using PWM technique. The reactive power is controlled by $\mathrm{I}_{\mathrm{d}}$. The STATCOM parameters are summarized in Table I [2]. The STATCOM capacity is limited by maximum current $\left(I_{\max }\right)$ given by equation (5).

$I_{\max }=\frac{\sqrt{2} S_{t}}{\sqrt{3} V_{t i}}$

where $S_{\mathrm{t}}$ is the transformer capacity in MVA and $\mathrm{V}_{\mathrm{ti}}$ is bus voltage.

\begin{tabular}{|l|c|}
\hline \multicolumn{2}{|c|}{ Table 1: Parameters Description of STATCOM [2] } \\
\hline \multicolumn{1}{|c|}{ Parameters } & Value \\
\hline $\begin{array}{l}\text { Transformer's } \\
\text { leakage impedance }\end{array}$ & $0.18 \mathrm{pu}$ \\
\hline $\begin{array}{l}\text { Converter's switching } \\
\text { frequency }\end{array}$ & $1650 \mathrm{~Hz}$ \\
\hline DC voltages PI controller & $\mathrm{K}_{\mathrm{p}}=10, \mathrm{~K}_{\mathrm{i}}=0.01$ \\
\hline AC voltages PI controller & $\mathrm{K}_{\mathrm{p}}=14, \mathrm{~K}_{\mathrm{i}}=0.01$ \\
\hline Inner $\mathrm{I}_{1 \mathrm{~d}}$ PI controller & $\mathrm{K}_{\mathrm{p}}=15, \mathrm{~K}_{\mathrm{i}}=0.001$ \\
\hline Inner $\mathrm{I}_{1 \mathrm{q}}$ PI controller & $\mathrm{K}_{\mathrm{p}}=15, \mathrm{~K}_{\mathrm{i}}=0.001$ \\
\hline
\end{tabular}

\section{SIMULATION RESULTS OF STUDY SYSTEM}

\subsection{Temporary Overvoltage}

LCC -HVDC station absorbs reactive power in range of 0.5 to 0.6 p.u. of rated DC power, which is usually supplied by filters and fixed capacitors connected to AC busbar [7, 8]. The reactive power consumption is negligible when converter is blocked. The excessive reactive power supplied by filters and shunt capacitors, results in temporary overvoltage. The case

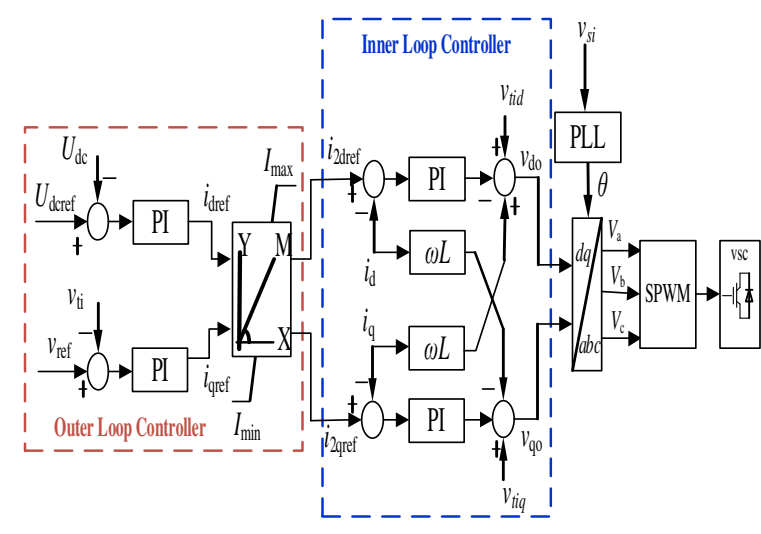

Fig.3: d-q decoupled controlled method of STATCOM [9]

is most severe when AC system is weak. TOV greatly depends on AC system's impedance, their angle and reactive power compensating devices connected to $\mathrm{AC}$ busbar.

The temporary overvoltage for all scenarios given in Table 2, is calculated using Power flow equation. These theoretical results are then validated using electromagnetic transient simulation program. Fig.4 shows the simulation results of temporary overvoltage

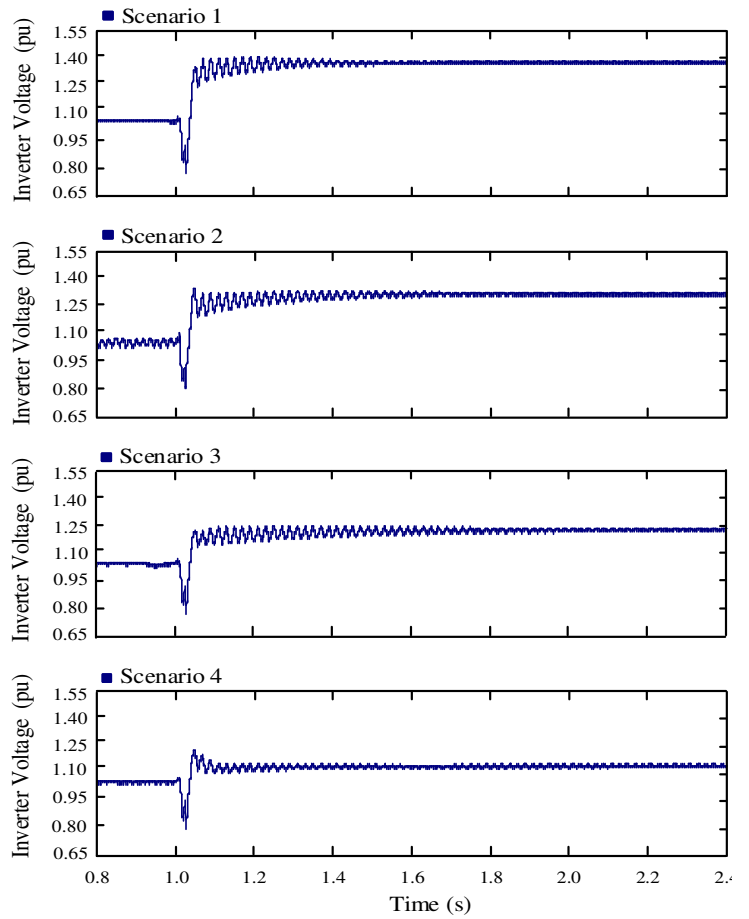

Fig.4: Temporary Overvoltage during Permanent DC Block 
at inverter side during permanent DC fault. Scenario 1 shows the worst case, as shunt capacitor is a passive device and results in reducing ESCR value. Larger the number of shunt capacitors connected to AC busbar, greater will be the value of TOV. The result is improved in Scenario 2 and 3. This is because of the fact that STATCOM is an active device and it has capability to control bus voltages by consuming reactive power. The greater the capacity of STATCOM, lower will be the TOV value. Fig.5. shows STATCOM capacity Vs TOV values for scenario 3 and 4.

\begin{tabular}{|l|c|c|c|c|}
\hline \multicolumn{5}{|c|}{ Table 2: Temporary Overvoltage Values } \\
\hline $\begin{array}{l}\text { Compensating } \\
\text { Schemes }\end{array}$ & Scenario & Scenario & Scenario & Scenario \\
TOV $(\mathrm{pu})$ & 1.4349 & 2 & 3 & 4 \\
\hline
\end{tabular}

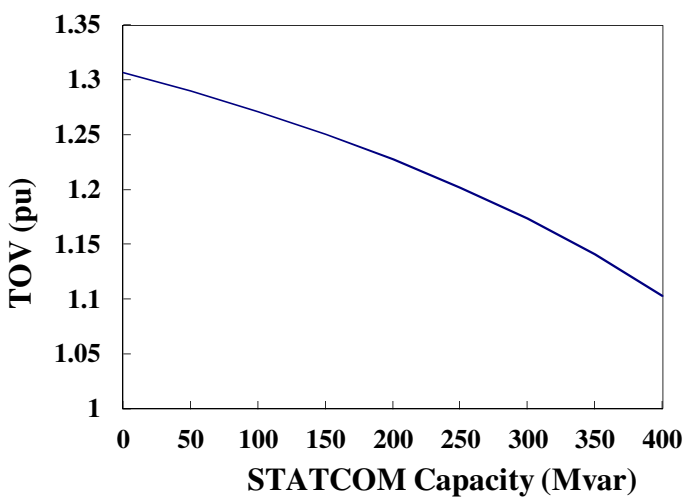

Fig.5: Temporary Overvoltages (pu) Vs Statcom Capacity Mvar (Scenario 3 and 4)

\subsection{Computation Failure}

Commutation failure is a worst dynamic event during inverter operation. It occurs when converter off going valve continues to conduct without transferring current to ongoing valve [10]. Commutation failure is mainly caused by low AC voltage condition or with increase in DC current [11]. It results in interruption of power flow to AC system. The interruption will be significant if AC system is weak. Moreover, the recovery process becomes difficult due to implication of large inverter firing angles and requirement of large amount of reactive power [2].

Commutation Failure Immunity Index (CFII) is used to evaluate the vulnerability of LCC converter to commutation failure. CFII is the ratio of worst critical fault MVA to rated DC power of converter [10].

CFII $=\frac{\text { Worst Critical Fauld MVA }}{\mathrm{P}_{\mathrm{dc}}}$

The above equation shows that greater the fault MVA, higher will be the CFII and less vulnerable is the LCC to Commutation Failure. CFII considers HVDC controls and AC system strength and their effect on commutation process. CFII uses electromagnetic transient simulation program to determine the susceptibility of LCC converters to commutation failure. Three-phase inductance fault with increasing severity is occurred at inverter bus, while continuously changing fault point on wave. Repeated simulations are conducted for different point on waves and critical fault levels at commutation failure occurs is then utilized to evaluate CFII. Table 3 indicates CFII values evaluated for all four scenarios, using multiple run function method in PSCAD/EMTDC. Scenario 1 and 2 have lower CFII values, as in both cases fixed capacitor is connected to inverter bus which results in decreasing ability of LCC-HVDC link against commutation failures. However, CFII values for scenario 3 and 4 are higher. This reveals that by adding STATCOM to LCC-HVDC results in strengthen the system and significantly immune to commutation failure. From table it is also clear that size of STATCOM has impact on CFII index. Scenario 4 (STATCOM 300 Mvar) with higher capacity has larger CFII value than scenario 3 (STATCOM 150 Mvar).

\begin{tabular}{|c|c|c|c|c|}
\hline \multicolumn{5}{|c|}{ Table 3: CFII values for all Four Scenarios } \\
\hline $\begin{array}{c}\text { Compensating } \\
\text { Schemes }\end{array}$ & $\begin{array}{c}\text { Scenario } \\
1\end{array}$ & $\begin{array}{c}\text { Scenario } \\
2\end{array}$ & $\begin{array}{c}\text { Scenario } \\
3\end{array}$ & $\begin{array}{c}\text { Scenario } \\
4\end{array}$ \\
\hline CFII (\%) & 9.72 & 11.35 & 12.61 & 14.47 \\
\hline
\end{tabular}

\subsection{Power Recovery Time}

Weak LCC-HVDC station has usually longer fault recovery times. This fault recovery time could be minimized in order to mitigate energy losses [12, 13]. In this work, DC power recovery time is utilized as fundamental metric to assess quantitatively the system recovery performance. Fault recovery time of DC power is defined as the time required for DC power to reinstate to $80 \%$ of pre fault values after fault 
clearance [2]. DC power recovery time for all four scenarios is evaluated, while applying different faults like single and three phase faults at inverter and rectifier side an DC temporary faults. The identical fault duration of five cycles ( 0.1 second) is used for all faults. The DC power recovery time for all four scenarios under various faults is shown in Fig 6. Scenario 1 shows largest fault recovery time due to absence of dynamic reactive power compensator at inverter busbar. The results are relatively improved due to addition of 150 Mvar STATCOM in Scenario 2 and 3. However, addition of 300 Mvar STATCOM regulates AC busbar voltage in a better war and significantly improves the fault recovery capability of LCC-HVDC system. Fig.7. summarizes dc power recovery times for all four scenarios.

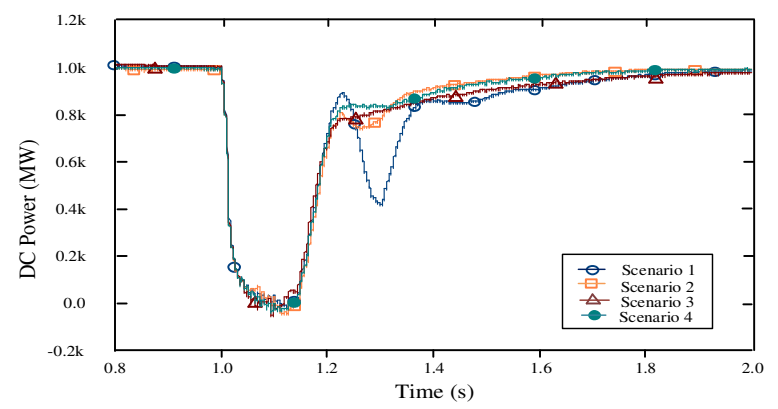

(a) Single-Phase Fault at Inverter Side

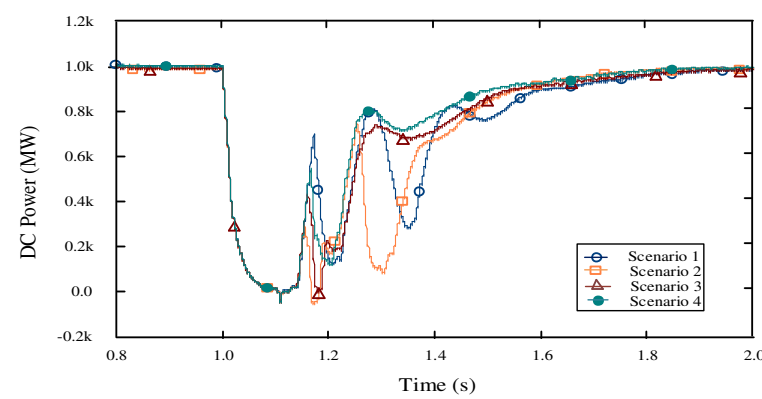

(b) Three-Phase Fault at Inverter Side

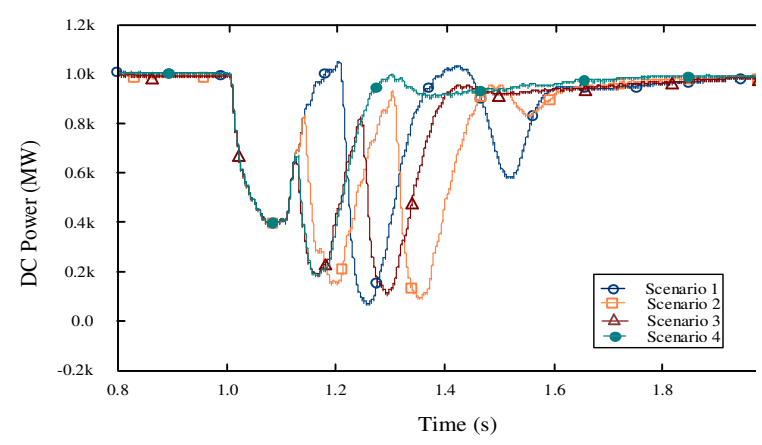

(c) Single-Phase Fault at Rectifier Side

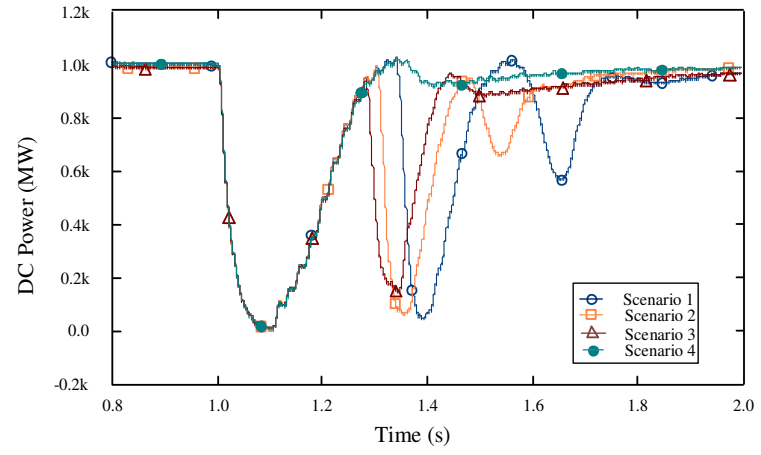

(d) Three-Phase Fault at Rectifier Side

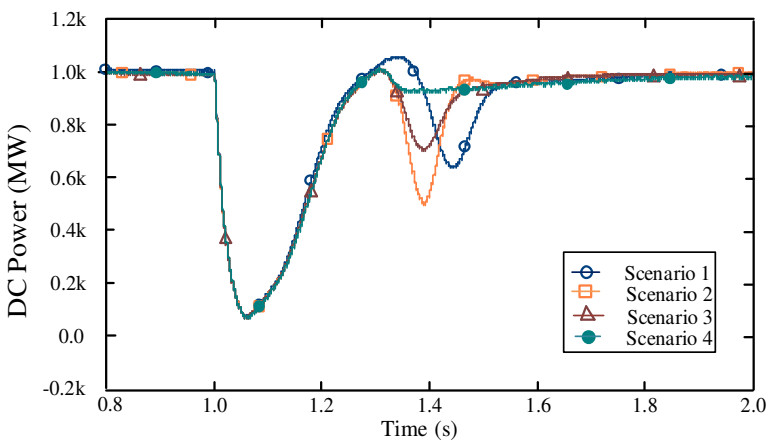

(e) DC Temporary Fault

Fig.6(a-e): DC Power Recovery Time for different Faults at different locations

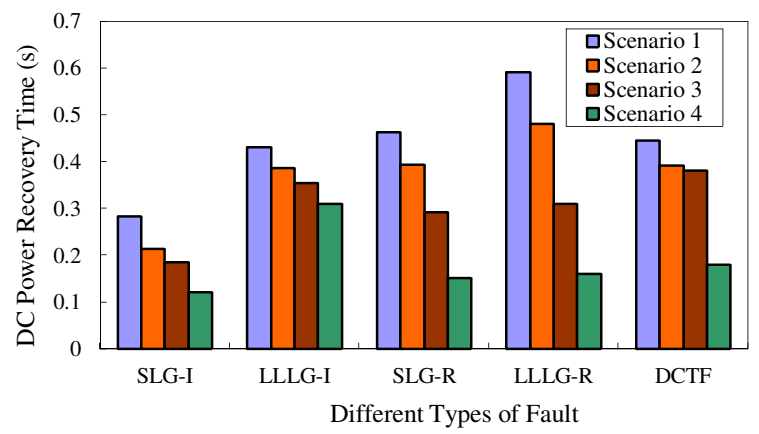

Fig. 7: Types of faults versus DC Power Recovery Time

\section{CONCLUSION}

This paper analysis the dynamic performances of various reactive power compensators of LCC-HVDC station linked into weak AC system. Four reactive power compensator scenarios are presented in order to analyze steady and transient states operation of weak LCC-HVDC terminals. Scenario 1 and 2 show worst results due to the fact that fixed capacitor decreases ESCR of system. Although scenario 3 give relatively 
good results, but the capacity of STATCOM is not as high that it can better support bus system in fault states. Scenario 4 , the optimum option shows very promising results. This is due to the reason that surplus reactive power capacity of STATCOM helps in regulating system bus voltage during transient state.

\section{REFERENCES}

1. Xue Y., Zhang X., Yang C., "Elimination of commutation failures of LCC HVDC system with controllable capacitors", IEEE Transactions on Power Systems, Vol.31, No. 4, pp.3289- 3299, Jul. 2016.

2. Rehman A. U., Guo C., Zhao C., "Quantitative index to evaluate the impact of reactive power compensators on AC system's strength of UHVDC transmission under hierarchical infeed mode", IET Generation, Transmission and Distribution, Vol. 14, No. 3, pp. 441-448, 142 2020.

3. Jovcic D., Ahmed K., "High-Voltage DirectCurrent Transmission Converters, Systems and Dc Grids", $1^{\text {st }}$ Edition, Wiley, 2015.

4. Nayak O. B., Gole A. M., Chapman D. G., Davies J. B., "Dynamic performance of static and synchronous compensators at an HVDC inverter bus in a very weak AC system", IEEE Transactions on Power Systems, Vol. 9, No. 3, pp. 1350-1358, August 1994.

5. Zhuang Y., Menzies R. W., Nayak O. B., Turanli H. M., "Dynamic performance of a STATCON at an HVDC inverter feeding a very weak AC system”, IEEE Transactions on Power Delivery, Vol. 11, No. 2, pp. 958-964, Apr. 1996.

6. Zhang Y., Gole A. M., "Comparison of the transient performance of STATCOM and Synchronous condenser at HVDC converter stations", Proceedings of the 11th IET International Conference on AC and DC Power Transmission, Birmingham, pp. 1-8, 2015.

7. Jos Arrillaga "High Voltage Direct Current Transmission", 2nd Edition, The Institution of Engineering and Technology, 2008.

8. Szechtman M., Wess T., Thio C. V., "A benchmark model for HVDC system studies", Proceedings of the International Conference on AC DC Power Transmission, pp. 374-378, 1991.
9. Schauder C., Mehta H., "Vector analysis and control of advanced static VAr compensators," in IEE Proceedings C-Generation, Transmission and Distribution, Vol. 140, No. 4, pp. 299-306, July 1993.

10. Rahimi A. M.E., Fellow G., Davies J. B., Fernando I.T., Kent K. L., "Commutation Failure Analysis in Multi-Infeed HVDC Systems", IEEE Transactions on Power Delivery, Vol 26, No.1,January 2011.

11. Guo C., Zhang Y., Gole A. M., Zhao C., "Analysis of Dual-Infeed HVDC With LCC-HVDC and VSC-HVDC", IEEE Transactions on Power Delivery, Vol. 27, No. 3, pp. 1529-1537, July 2012.

12. "IEEE Guide for Planning DC Links Terminating at AC Locations Having Low Short-Circuit Capacities", IEEE Standard 1204-1997, June1997.

13. Rehman A. U., Zhao C., Guo C., "Coordinated control strategy for transient performance improvement of LCC based HVDC transmission system with STATCOM under weak AC grid", Proceedings of the 2nd IEEE Conference on Energy Internet and Energy System Integration (EI2), pp. 1-6, Beijing, 2018.

\section{APPENDIX}

The magnitude and angle of AC source voltage at inverter side is calculated using following equations [11]. These equations are also utilized for evaluation of temporary overvoltage.

$$
\begin{aligned}
& \mathrm{I}_{\mathrm{d}}=\frac{\mathrm{U}[\cos \gamma-\cos (\gamma+\mu)]}{\sqrt{2} \mathrm{TX}} \\
& \mathrm{U}_{\mathrm{d}}=\frac{3 \sqrt{2} \mathrm{U}}{\pi \mathrm{T}} \cos \gamma-\frac{3}{\pi} \mathrm{X}_{\mathrm{T}} \mathrm{I}_{\mathrm{d}} \\
& \mathrm{P}_{\mathrm{d}}=\mathrm{U}_{\mathrm{d}} \mathrm{I}_{\mathrm{d}} \\
& \mathrm{Q}_{\mathrm{d}}=\mathrm{P}_{\mathrm{d}} \tan \emptyset \\
& \cos \emptyset=-\frac{\cos \gamma+\cos (\gamma+\mu)}{2} \\
& \mathrm{P}_{\mathrm{ac}}=\frac{\left[\mathrm{U}^{2} \cos \theta-\mathrm{EU} \cos (\delta+\theta)\right]}{|\mathrm{Z}|} \\
& \mathrm{Q}_{\mathrm{ac}}=\frac{\left[\mathrm{U}^{2} \sin \theta-\mathrm{EU} \sin (\delta+\theta)\right]}{|\mathrm{Z}|} \\
& \mathrm{Q}_{\mathrm{c}}=\mathrm{B}_{\mathrm{c}} \mathrm{U}^{2} \\
& \mathrm{P}_{\mathrm{d}}-\mathrm{P}_{\mathrm{ac}}=0 \\
& -\mathrm{Q}_{\mathrm{d}}+\mathrm{Q}_{\mathrm{ac}}-\mathrm{Q}_{\mathrm{c}}=0
\end{aligned}
$$

